\title{
Papillary Thyroid Carcinoma During Etanercept Therapy in a Patient with Psoriatic Arthritis
}

\author{
Ilker Ilhanli ${ }^{1, *}$, Necip Guder ${ }^{2}$ \\ ${ }^{1}$ Department of Physical Medicine and Rehabilitation, School of Medicine, Giresun University, Giresun, Turkey \\ ${ }^{2}$ Physical Medicine and Rehabilitation State Hospital, Giresun, Turkey
}

Email address:

ilkerilhanli@hotmail.com (I. Ilhanli)

\section{To cite this article:}

Ilker Ilhanli, Necip Guder. Papillary Thyroid Carcinoma During Etanercept Therapy in a Patient with Psoriatic Arthritis. Science Journal of Clinical Medicine. Vol. 4, No. 5, 2015, pp. 93-95. doi: 10.11648/j.sjcm.20150405.13

\begin{abstract}
Potential for developing malignancies with Tumor necrosis alpha blockers (Anti-TNF $\alpha$ ) in romatologic diseases is an important question in our minds, contrary to the proved efficacy of them. To our knowledge, yet no case report has been established about papillary thyroid carcinoma during etanercept therapy for psoriatic arthritis. Here we reported a patient who was diagnosed as papillary thyroid carcinoma while she was using etanercept for psoriatic arthritis. She had medical history for familial trait of carcinoma. Radioactive iodine therapy was administered after the surgery. We preferred to stop etanercept therapy and there was no increase in clinical and laboratory disease activity.
\end{abstract}

Keywords: Anti-TNFa, Etanercept, Psoriasis, Papillary Thyroid Carcinoma

\section{Introduction}

In recent years usage of the Tumor necrosis alpha blockers (Anti-TNF $\alpha$ ) in romatologic diseases has been increased and their efficacy has been proved. Etanercept is a fusion protein resembling TNF receptors type-II, which acts by blocking circulating TNF and lymphotoxin-a [1]. It is approved for the treatment of Rheumatoid arthritis, Psoriatic arthritis, Ankylosing spondylitis, Moderate to severe plaque psoriasis and Severely active polyarticular juvenile idiopathic arthritis in children aged 2 years and older [1]. While the importance of these drugs is folding up, some questions are appearing in the minds, like whether they lead or facilitate the malign process. Thyroid cancer is the most common malignant tumor of the endocrine system. The incidence of thyroid cancers is increasing worldwide. Some somatic oncogene mutations (BRAF, NRAS, HRAS, KRAS) as well as gene translocations (RET/PTC, PAX8/PPAR-gamma) have been associated with the development of thyroid cancer [2]. The most frequent type of thyroid malignancy is papillary carcinoma. Here we reported a patient who was diagnosed as papillary thyroid carcinoma (Fig 1.) while she was using etanercept for psoriatic arthritis.

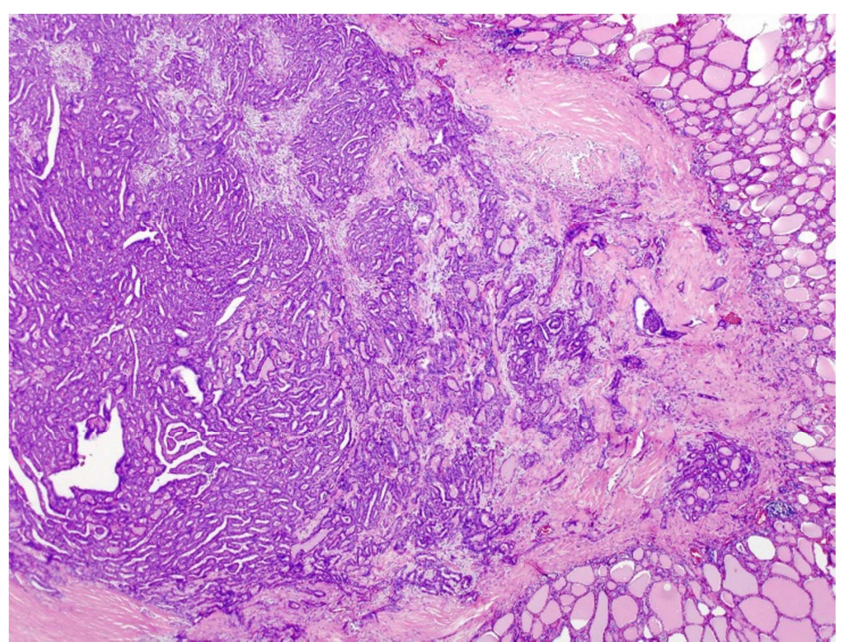

Fig. 1. Thyroid papillary carcinoma hystopathology.

\section{Case}

A52 years old female patient presented to our clinic with the pathological diagnose of papillary thyroid carcinoma while she was using etanercept for psoriatic arthritis. Fifteen years ago she was diagnosed as psoriatic arthritis and she had used methotrexate and than leflunamide but these drugs were stopped because of the increased liver enzymes and 
etanercept therapy was started. After fourteen months, while the clinical and the laboratory disease activity was going suppressed, she has been diagnosed as multinodular goiter by endocrinology and they preferred to send her under surgery. We stopped etanercept therapy four weeks before the surgery and she preferred to go under surgery in another university hospital. A total thyroidectomy surgery was performed and pathology had diagnosed her as papillary thyroid carcinoma with one lymphatic nod metastasis. They had used to give her radioactive iodine therapy after the surgery and one month after the surgery they had started etanercept therapy again. Patient presented to our clinic while she was using etanercept for one month. We stopped etanercept and started prednisolone $10 \mathrm{mg} / \mathrm{per}$ day. There was no increase in clinical and laboratory disease activity. When we deepened the history of the patient, we learned that her mother was diagnosed as thyroid papillary carcinoma, too.

\section{Discussion}

Thyroid cancer is the most common malignant tumor of the endocrine system. The most frequent type of thyroid malignancy is papillary carcinoma. These tumors frequently have genetic alterations leading to the activation of the mitogen-activated protein kinase (MAPK) signaling pathway. Most common mutations in papillary carcinomas are point mutations of the BRAF and RAS genes and RET/PTC rearrangement. These genetic alterations are found in $>70 \%$ of papillary carcinomas and they rarely overlap in the same tumor [3]. TNF-alpha is a pluripotent cytokine that induces both proapoptotic and anti-apoptotic effects on thyroid carcinoma cells [4]. TRAIL potently and selectively kills thyroid carcinoma cells. Consequently, TRAIL is the only member of the family with significant anticancer activity for thyroid cancer [4]. Increasing evidence suggests that apoptosis plays an important role in the pathogenesis of autoimmune and proliferative thyroid diseases, and that the apoptotic pathways involved are complex and highly regulated. On the other hand, an imbalance between thyroid cell proliferation and cell death may be crucial for goiter formation or cancer development and progression [5]. The cancer risk seems to be increased in psoriasis patients when compared with the healthy population. In United Kingdom a retrospective study was made among 65 years and older patients by using the General Practice Research Database and lymphoma risk was found 3 times higher in psoriasis patients than the healthy population [6]. Also in another retrospective study which used U.S.A. Medicaid Database it was found that malignancy risk including lymphoma was higher in psoriasis patients and the risk was higher in patients with severe psoriasis [7]. Wolfe reported that anti-TNF therapy isn't associated with major cancers in rheumatoid arthritis patients; however, melanoma and the other skin cancers seem to be more frequent in rheumatoid arthritis patients using infliximab and etanercept [8]. Bongartz reported the odds ratio of malignancy 3,3 $(95 \%$ CI; 1,2-9,1) in patients using adalimumab or infliximab therapy in a systematic review and metaanalysis [9]. FDA reported a metaanalysis including the relative malignancy risks for anti-TNF therapies. Relative malignancy risk was 0,86 for etanercept, 5 for infliximab and 1,75 was for adalimumab [10]. Diak et al. reported papillary thyroid carcinoma in a patient who was under etanercept treatment for juvenil idiopatic arthritis [11]. Although there is a report of papillary thyroid carcinoma in a patient with severe psoriasis receiving adalimumab [12], we couldn't find data for papillary thyroid carcinoma during etanercept treatment for psoriatic arthritis. In a recently published article, it is reported that malignancy rates were higher in psoriasis patients than the general population, but the anti-TNF treatments did not appear to increase malignancy risk [13].

\section{Conclusion}

In our opinion this is a hereditary case and may be with the predisposition of etanercept. We should take attention to papillary thyroid carcinoma, especially with the medical history for familial trait of carcinoma while using antiTNF $\alpha$.

\section{References}

[1] Georgakopoulou EA, Andreadis D, Arvanitidis E, Loumou P. Biologic agents and oral diseases--an update on clinical applications. Acta dermatovenerologica Croatica: ADC. 2013; 21: $24-34$.

[2] Tobiás B, Halászlaki C, Balla B et al. Genetic Alterations in Hungarian Patients with Papillary Thyroid Cancer. Pathol Oncol Res. 2015 Aug 11. [Epub ahead of print]

[3] Nikiforov YE. Thyroid carcinoma: molecular pathways and yherapeutic targets. Mod Pathol. 2008; 21(2):37-43.

[4] Mitsiades CS, Poulaki V, Mitsiades N. The role of apoptosisinducing receptors of the tumor necrosis factor family in thyroid cancer. J. Endocrinol. 2003 Aug; 178(2): 205-216.

[5] Tsatsoulis A. The role of apoptosis in thyroid disease. Minerva Med. 2002; 93(3): 169-180.

[6] Gelfand JM, Berlin J, Van Voorhees A, Margolis DJ. Lymphoma rates are low but increased in patients with psoriasis: results from a population based cohort study in the United Kingdom. Arch Dermatol. 2003; 139: 1425-1429.

[7] Margolis D, Bilker W, Hennessy S, Vittorio C, Santanna J, Strom BL. The risk of malignancy associated with psoriasis. Arch Dermatol. 2001; 137:778-783.

[8] Wolfe F, Michaud K. The association of new cases of cancer with biologic therapy. Arthritis Rheum. 2006; 54: 549.

[9] Bongartz T, Sutton AJ, Sweeting MJ, Buchan I, Matteson EL, Montori V. Anti TNF antibody therapy in rheumatoid arthritis and the risk of serious infections and malignancies: Systematic review and metaanalysis of rare harmful effects in randomized controlled trials. J Am Med Assoc. 2006; 295: 2275-2285.

[10] Okada SK, Siegel JN. Risk of serious infections and malignancies with antiTNF antibody therapy in rheumatoid arthritis. J Am Med Assoc. 2006; 296: 2201-2202. 
[11] Diak P, Siegel J, La Grenade L, Choi L, Lemery S, McMahon A. Tumor necrosis factor $\alpha$ blockers and malignancy in children: Forty-eight cases reported to the food and drug administration. Arthritis \& Rheumatism. 2010; 62(8): 25172524

[12] Lee JJ, Mann JA, Blauvelt A. Papillary thyroid carcinoma in a patient with severe psoriasis receiving adalimumab. J Am Acad Dermatol. 2011; 64(5): 999-1000.
[13] Kimball AB, Schenfeld J, Accortt NA, Anthony MS, Rothman KJ, Pariser D. Cohort Study of Malignancies and Hospitalised Infectious Events in Treated and Untreated Patients with Psoriasis and a General Population in the United States. Br J Dermatol. 2015 Aug 12. doi: 10.1111/bjd.14068. [Epub ahead of print]. 